\title{
Getting lost in a jungle: A commentary on Shenkar
}

\author{
Vladimir PUCIK \\ Michigan Business School, The University of Michigan, Ann \\ Arbor, MI 48109, USA
}

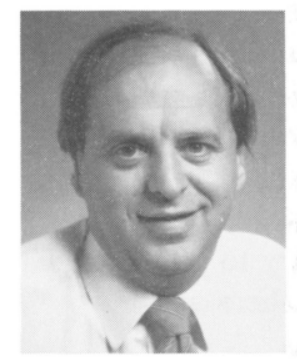

Vladimir Pucik is Assistant Professor of International Business and Organizational Behavior at the School of Business, The University of Michigan. $\mathrm{He}$ was born in Prague, Czechoslovakia where he studied international economics, law, and political science. Later, he received a master's degree in international affairs - specializing in East Asia - and a Ph.D. in business administration from Columbia University. His research interests include problems of international competition, international joint ventures, linkage of competitive strategies with human resource management, and comparative management with a particular emphasis on Japan. He has published extensively in academic and professional journals, such as the Academy of Management Review, Columbia Journal of World Business, Human Resource Management, Organizational Dynamics, and Japan Economic Journal, as well as contributed to a number of books and monographs on the area of international business.

Shenkar's contribution to the discussion on the Japanese management system is based on two points. He believes that past explanations of the Japanese management system disregarded interdependencies among Japanese managerial principles and environmental variables. To rectify this alleged shortcoming, and in order to build a model that reflects Japanese management as a system, he proceeds to review what he considers the key practices of Japanese management in light of potential environmental influences. What did we learn? Unfortunately, in spite of the author's best intentions and considerable efforts, we learned nothing that we did not know before. What caused this failure?

First of all, the very premise of Shenkar's article - the lack of attention to interdependencies - is not supported by even a cursory review of past serious research on Japanese management and

North-Holland

Human Systems Management 7 (1988) 231-232 organizations. The issue of environmental interdependence in one way or another has dominated the debate on this topic ever since Abegglen's early work on Japanese factory organization [1]. However, most of this literature is ignored by Shenkar. To stay with just the English-language publications, the 'missing' list includes fundamental contributions by Dore [6], Rohlen [9], Clark [3], and Cole [4], not to mention several key works published during the 1980's [7,10]. The potential dysfunctions of some of the practices presented have also been reviewed before.

Now, even though the purpose of Shenkar's undertaking may not be novel, a meta-analysis or even a concise summary of the existing literature may still be useful, especially for readers of general management journals such as Human Systems Management. However, the presented review is not satisfactory on several dimensions: it lacks an integrated theoretical foundation, it rests mainly on oversimplifications concerning organizational practices in Japan, and contains too many statements that are actually incorrect.

To begin with, I doubt that the seven practices analyzed by Shenkar are indeed the essence of the Japanese management system. Some of them are clearly more of a myth than reality (e.g., seniority or consensual decision making), others could be defined with more precision (e.g., life-time employment). Yet, this is not the main point of my concern. What I find most disappointing is the conceptual confusion emanating from the absence of a coherent theory. In essence, we are treated to a series of theoretically disjointed generalizations - some correct, some incorrect - asserting that certain features of some Japanese organizations are related to specific environmental variables chosen from a large 'pot' at the author's discretion.

No theory is presented, or even referred to, justifying the selection of the practices supposedly representing 'Japanese management'. The review of the various interdependencies is unsystematic. Is it a coincidence or the author's intent that 
among the environmental factors, the culture-related variables dominate? Opinions fitting Shenkar's implicit model of the relevant environment are presented as factual evidence, in particular numerous references to the impact of Confucianism derived from Morishima [8], while interpretations and data pointing to alternative causal directions are not considered.

To compound the problems, too many assertions are factually off-the-mark, or do not reflect the dynamic reality of the Japanese business system. For example, the origins of the 'just-in-time' system is presented in the context of scarcity of space and consolidation of suppliers. In fact, the JIT system evolved from particular financial and market conditions in Toyota and the consolidation of suppliers was a consequence not the prerequisite of JIT implementation [5]. Shenkar also proposes that JIT is intertwined with the manufacturing strategy of 'low product variety'. This, of course, was the strategy of the 1970's. Today, the JIT system in its most advanced form is used exactly for an opposite purpose - to support efficient and flexible production of a maximum number of product varieties [2].

Even Morishima, who seems to be Shenkar's favored source, is not cited properly. According to Shenkar, Morishima suggests that the introduction of the seniority wage structure was made possible by the institutionalization of Confucian morality. In fact, Morishima says nearly the opposite: '(in spite of Confucian education)...the spirit of loyalty was still a fairly rare commodity, and to that extent a company had to make special payments with a view of procuring it' [8, p. 105]. The list of similar omissions and misunderstandings is much longer, but my skepticism about Shenkar's approach goes beyond the question of judgment on what are the 'fundamental' principles of Japanese management, or the validity of the evidence used to support a point.

It may seem a harsh judgment, but I believe that Shenkar is not familiar enough with the phenomena which he wants to study (although he probably knows more about Japan than most of the self-appointed gurus ready to write a book about Japan after a two-week sightseeing tour). This would not have mattered only a few years ago, when our level of knowledge of Japanese management and organizations was marginal at best. Today, however, the field of 'Japanology' in organizational sciences is a well-developed discipline. Pushing the boundaries of our knowledge became much more difficult, as the standards for judging new contributions are justifiably getting higher.

The much-needed progress in refining our understanding of Japanese organizations will come only from EXECUTING the kind of research agenda that Shenkar outlined in his closing comments, not from another round of pontification about systems and relationships. It also has to be based on a thorough understanding of where the field is today, on a first-hand familiarity with Japan as well as on the adoption of a multidisciplinary perspective. Without such foundations, it is not surprising that some travellers may get lost in the jungle, no matter how noble their intentions, no matter how hard they try to get through, or even if there is no jungle out there at all.

\section{References}

[1] Abegglen, J.C., The Japanese factory: Aspects of its social organization (The Free Press, Glencoe, IL, 1958).

[2] Abegglen, J.C. and G. Stalk, Jr., Kaisha. The Japanese corporation (Basic Brooks, New Yórk, 1985).

[3] Clark, R., The Japanese company (Yale University Press, New Haven, CT, 1979).

[4] Cole, R.E., Work, mobility \& participation. A comprehensive study of American and Japanese industry (California University Press, Berkeley, CA, 1979).

[5] Cusumano, M.A., The Japanese automobile industry. Technology \& management at Nissan and Toyota (The Council on East Asian Studies, Harvard University, Cambridge, MA 1985).

[6] Dore, R.P., British factory-Japanese factory: The origins of national diversity in industrial relations (California University Press, Berkeley, CA, 1973).

[7] Gordon, A., The evolution of labor relations in Japan. Heavy industry, 1853-1955 (The Council on East Asian Studies, Harvard University, Cambridge, MA, 1985).

[8] Morishima, M., Why has Japan succeeded: Western technology and the Japanese ethos. (Cambridge University Press, Cambridge, 1982).

[9] Rohlen, T.P., For harmony and strength: Japanese whitecollar organization in anthropological perspective (California University Press, Berkeley, CA, 1974).

[10] Shirai, T., Ed., Contemporary industrial relations in Japan (Wisconsin University Press, Madison, WI, 1983). 